\title{
ИНТЕРПРЕТАЦИЯ
}

\author{
М.Е. Бойко
}

\section{РЕАЛИЗМ И ТРЁХОПЕРАТОРНЫЙ МЕТОД ИНТЕРПРЕТАЦИИ}

Аннотация. Предметом статьи является проблема дефиниции литературных терминов "реализм», "социальный реализм», "психологический реализм» и «метафизический реализм». Как правило, реалистическими предлагается считать тексты, удовлетворяющие некоторой совокупности критериев. Этот «классический» подход на практике приводит к многочисленным трудностям и противоречиям. В частности, в его рамках не удаётся разрешить проблему с классификацией “реализма в высшем смысле» Ф.М. Достоевского. Высказывалось предложение элиминировать из научного дискурса термин "реализм» по причине его самопротиворечивости. В статье разрабатывается альтернативный подход к определению термина "реализм», согласно которому "реалистичность»-это эффект, возникающий при специфических способах интерпретации текста. Доказывается, что релевантная и логически непротиворечивая совокупность критериев реалистичности невозможна. Таким образом, классический подход к проблеме реализма основан на ложном допущении. На конкретных примерах разрабатывается и апробируется трёхоператорный метод абстрактная модель тех способов интерпретации текста, при использовании которых возникает эффект «реалистичности» текста. Демонстрируется, что новый подход не порождает трудностей и противоречий классического подхода.

Ключевые слова: интерпретация, метафизический реализм, полифония, реализм, психологический реализм, семантический оператор, социальный реализм, структурализм, творческий метод, хронотоп.

Abstract. The subject of the research is the definition of literary terms 'realism', 'social realism', 'psychological realism' and 'metaphysical realism'. As a rule, texts that satisfy a number of criteria are considered to be realistic. However, such conventional approach creates numerious difficulties and contradictions. In particular, it does not allow to solve the problem of classification of 'realism in the highest meaning' as it was presented by Fyodor Dostoyevsky. There has been an opinion that the term 'realism' should be eliminated from the scientific discourse because it is too contradictory. The author of the present article offers an alternative approach to the definition of the term 'realism'. According to the author, realism is the effect created in the process of applying specific means of text interpretation. It is provede that relevant and logically uncontroversial combination of realism criteria is impossible. Thus, the conventional approach to the problem of realism is based on the wrong assumption. Based on particular examples, the author of the article develops and tries out the so-called three-operator method, i.e. abstract model of intepretation methods which application creates the effect of text realism. It is also demonstrated that the new approach does not create the difficulties and contradictions the conventional approach does.

Key words: semantic operator, psychological realism, realism, polyphony, metaphysical realism, interpretation, social realism, structuralism, creative method, chronotope.

\section{1. Постановка проблемы}

Проблема, связанная с тем, что понимать под словом «реализм» и какие именно тексты считать «реалистическими», имеет уже более чем полуторавековую историю. Поставлена в отечественной науке эта проблема была ещё до введения П.В. Анненковым в критический обиход самого термина «реализм» [1, с. 39], и условной точкой отсчёта можно считать статьи В.Г. Белинского о «натуральной школе». Библиография по данной теме включает многие тысячи наименований, и неиссякающий по- ток таких работ свидетельствует о том, что удовлетворительное решение проблемы до сих пор не найдено.

Несмотря на многочисленные нюансы, все известные нам подходы к определению «реализма» и его подтипов, строятся по одной и той же схеме. Как правило, т. н. «реалистические тексты» противопоставляются т. н. «нереалистическим текстам», и реалистическими предлагается считать художественные тексты, удовлетворяющие некоторой совокупности критериев $\left\{\mathrm{k}_{1}, \mathrm{k}_{2} \ldots \mathrm{k}_{\mathrm{n}}\right\}$. Все подходы, строящиеся по такой схеме, мы будем считать раз- 
новидностями классического подхода к проблеме реализма. Подчеркнём, что в данном исследовании классическим подходом называется некоторая абстракция, универсалия, обозначающая тun большого количества конкретных подходов к проблеме реализма, предложенных различными исследователями.

Разногласия среди сторонников классического подхода возникают относительно совокупности критериев реалистичности $\left\{\mathrm{k}_{1}, \mathrm{k}_{2} \ldots \mathrm{k}_{\mathrm{n}}\right\}$ : какие критерии в неё включать, а какие нет, какие критерии являются необходимыми, а какие достаточными. Диапазон мнений можно оценить, сравнив, например, следующие критерии:

1) «помимо правдивости деталей, правдивость воспроизведения типичных характеров в типичных обстоятельствах» (Ф. Энгельс) [2, с. 11];

2) «чем более глубокое и всеобъемлющее понимание законов существования мира во всех его измерениях предоставляет произведение, тем более реалистичным оно является» (К.А.Степанян) [3, с. 17].

Мы видим, что предлагаемые критерии в корне различны, но сами подходы структурно идентичны, строятся по одной и той же схеме и могут, следовательно, рассматриваться как разновидности общего классического подхода.

Отсутствие прочного согласия относительно критериев реалистичности свидетельствует, на наш взгляд, о неудовлетворительности классического подхода уже на уровне его схемы, структуры, заложенных в нём эксплицитных и имплицитных допущений. Закономерной реакцией на неудачу классического подхода является предложение В.П. Руднева вообще отказаться от термина «реализм» как самопротиворечивого: «понятие художественного реализма является противоречивым, оно не описывает никакую специфическую область художественного опыта, и лучше всего от него отказаться» [4, с. 192-193].

Поскольку мы предлагаем кардинально иной подход к проблеме реализма, мы не будем вдаваться в детали различных вариаций классического подхода. Мы оттолкнёмся от частной проблемы классического подхода, связанной с классификацией «реализма в высшем смысле» - творческого метода Ф.М. Достоевского, согласно его собственному определению [5, с. 65].

\section{2. Реализм в высшем смысле}

Неудачность с научной точки зрения термина, предложенного Достоевским для обозначения собственного творческого метода, очевидна. Если признать научный статус термина «реализм в высшем смысле», то ничто не мешает поставить вопрос о «романтизме в высшем смысле», «сюжете в высшем смысле», «персонаже в высшем смысле» и т. д., а это чревато удвоением всего научного словаря. В этой связи понятно желание исследователей более точно зафиксировать главную особенность творческого метода Достоевского. Кроме традиционного обозначения «психологический реализм», широко используются также выражения «метафизический реализм» (Ю.В. Мамлеев), «христианский реализм» (3.Н. Захаров), М. Джоунс предложил оксюморонный термин «фантастический реализм» - налицо желание прибавить к термину «реализм» некий «сущностный» эпитет.

Большое влияние приобрела теория М.М. Бахтина, согласно которой основной особенностью романов Достоевского является «множественность самостоятельных и неслиянных голосов и сознаний, подлинная полифония полноценных голосов» $[6$, с. 10]. П.Х. Тороп развил и модифицировал теорию Бахтина, и до сих пор это, пожалуй, самая практичная и логичная интерпретация творческого метода Достоевского.

На основе анализа пространственно-временных связей в романе «Преступление и наказание» Тороп показал, что «в романе можно операционально выделить три сосуществующих уровня (хронотопа): топографический хронотоп, психологический хронотоп и метафизический хронотоп» [7, с. 139].

Топографический хронотоп связан с «узнаваемостью в романе конкретного исторического времени и места, а также событий» [7, с. 139-140]. На этом уровне роман гомофоничен и ведётся от лица невидимого всеведущего рассказчика. Психологический уровень - это хронотоп персонажей: «Вместо невидимого описывающего на этом уровне перед нами мир автономных голосов, вместо гомофонии - полифония» [7, с. 140]. Метафизический хронотоп Тороп рассматривает как уровень описания и создания метаязыка: «Метаязык задаётся не просто описывающим, а его главной идеей - и оказывается, что на более глубоком уровне полифония является лишь сосуществованием разных трансформаций этой идеи. "Невидимый” автор становится на этом уровне видимым в том смысле, что именно он устанавливает язык описания. Таким образом, уровень топографического хронотопа является наблюдаемым миром, уровень психологического хронотопа - миром наблюдателей и метафизический хронотоп - миром устанавливающего язык описания» [7, с. 141]. Также Тороп отмечает, что метафизический уровень связан с «сакральными и сакрализованными идеями» [8, с. 86] и что применительно к этому уровню правильнее говорить не о гомофонии или полифонии, а о гетерофонии [7, с. 141]. 


\section{Филология: научные исследования 3(19) • 2015}

Идея Торопа в общих чертах представляется нам плодотворной, а вот его трактовка метафизического хронотопа - не совсем ясной и излишне усложнённой. Более удачную трактовку предложил, на наш взгляд, Ю.В. Мамлеев, согласно которому метафизический хронотоп - это не просто уровень метаязыка, а само сакральное метафизическое пространство, в котором разыгрываются сакральные и метафизические сюжеты. На этот уровень приводит «такой способ “вхождения” в трансцендентную сферу, который опирается на априорную, внутреннюю метафизическую данность (реальность), присущую какому-либо человеку или группе людей» $[9$, с. 42]. Впрочем, возможна и другая авторская стратегия: «Практически роль метафизической ситуации в данном произведении может даже играть философско-метафизическая система, уже в современно-классическом понимании этого слова. Теоретически даже такая громоздкая, как система Гегеля. Правда, такие построения обычно являются односторонним рационалистическим толкованием глубоких реальностей, известных древней традиции, а не метафизикой в собственном смысле этого слова. И тем не менее, поскольку в них часто содержится отблеск, пусть даже анти-тень чистой метафизики, то они могут быть пригодны для этой цели» $[9$, с. 103].

Ещё одна поправка к концепции Торопа заключается в том, что термин «топографический» не совсем удачен, ибо речь идёт не только о пространственной конкретизации, но также о временной и социальной конкретизациях. Более уместным нам представляется выражение «социальный уровень», поскольку на этом уровне сопоставляются материально-предметные наполнения диегетического и реального миров, а также царящие в них социальные отношения. Причём социальные отношения рассматриваются с объективной стороны, как общие для всех представителей диегетического социума (это важная оговорка, поскольку социальные отношения осмысляются также на психологическом уровне - через чувства персонажей).

П.Х. Тороп и Ю.В. Мамлеев убедительно показали, что в романах Достоевского диегетический мир изображается в трёх различных «сечениях»социальном, психологическом и метафизическом. Проблема с классификацией творческого метода Достоевского возникла из-за того, что эту «троякость» сложно зафиксировать каким-то одним «сущностным» эпитетом. Достоевский одновременно является реалистом социальным, реалистом психологическим и реалистом метафизическим.

Ещё более важный результат заключается в том, что каждый из трёх уровней управляется своими законами, и законы каждого уровня, вообще говоря, логически противоречат законам других уровней - например, логически противоречат друг другу принципы гомофонии, полифонии и гетерофонии. Отсюда следует, что невозможна релевантная и логически непротиворечивая совокупность критериев реалистичности $\left\{\mathrm{k}_{1}, \mathrm{k}_{2} \ldots \mathrm{k}_{\mathrm{n}}\right\}$, применимая к художественным произведениям, взятым целиком. Следовательно, классический подход основан на ложном допущении, и с его помощью проблема реализма не может быть разрешена в принципе.

Но концепция П.Х. Торопа имеет ещё и то преимущество, что она может быть формализована, и в следующем разделе мы покажем, каким именно образом.

\section{3. Трёхоператорный метод интерпретации}

Всякий текст с семиотической точки зрения можно рассматривать в трёх аспектах, соответствующих трём разделам семиотики - синтактике, семантике и прагматике. Его можно рассматривать как синтаксическую структуру, как семантический континуум (пространство смыслов) и некий прагматический инструмент, с помощью которого читатель может внутренне измениться и внести коррективы в свои отношения с окружающим миром.

Мы можем ввести три семантических оператора $\hat{S}, \hat{P}$ и $\hat{M}$, каждый из которых выделяет из семантического континуума произведения пласт смыслов, относящихся к конкретному уровню - социальному, психологическому и метафизическому уровням соответственно. По сути, это сокращённое обозначение тех действий, которые совершает интерпретатор, когда «изолирует» один из трёх уровней произведения, чтобы проанализировать его для рассмотрения его безотносительно к двум другим уровням. Символически это обозначается как действие оператора на данный текст Т: $\hat{S} T$, $\hat{P} T$ и $\hat{M} T$ (оператор обозначается буквой с циркумфлексом).

Оператор $\hat{S}$ выделяет те смыслы, которые имеют отношение к материально-предметному миру произведения, к объективной стороне социальных отношений персонажей.

Оператор $\hat{P}$ выделяет те смыслы, которые имеют отношение к внутренним мирам и характерам персонажей, к их взаимоотношениям, рассмотренным через их чувства, мысли, субъективное восприятие.

Оператор $\hat{M}$ выделяет те смыслы, которые имеют отношение к сакральному архисюжету произведения, к высшей духовной реальности, к духовным поискам персонажей.

Поскольку каждый из трёх уровней может быть в произведении (как, например, в романах Достоевского) тщательно проработан и детализирован, нам 
понадобится ещё один вспомогательный оператор $\hat{R}$, сводящий каждый из трёх пластов смыслов к некой главной идее, «теме». Назовём его «оператором редукции к теме». По сути, это та же самая процедура, с помощью которой интерпретатор сопоставляет некоторому длинному тексту краткое описание его содержания. А.-Ж. Греймас называл эту аналогичную процедуру «уплотнением» [10, с. 107].

Теперь мы можем записать:

$$
\begin{aligned}
& \hat{R} \hat{S} T=s(T), \\
& \hat{R} \hat{P} T=p(T), \\
& \hat{R} \hat{M} T=m(T),
\end{aligned}
$$

где $\mathrm{s}(\mathrm{T}), \mathrm{p}(\mathrm{T})$ и $\mathrm{m}(\mathrm{T})$ - главные социальная, психологическая и метафизическая темы произведения соответственно.

Пусть Т - это роман Достоевского «Преступление и наказание», тогда $s(\mathrm{~T})=$ «криминальная история об убийстве петербургским студентом Раскольниковым в середине XIX века старухи-процентщицы», $\mathrm{p}(\mathrm{T})$ = «чувства и сложные взаимоотношения Раскольникова, его матери, сестры, Сони Мармеладовой и других персонажей»; $\mathrm{m}(\mathrm{T})=$ «духовное возрождение Раскольникова, воспроизводящее сакральный сюжет - воскрешение Лазаря».

Если Т $=$ «Обломов» И.А. Гончарова, тогда $\mathrm{s}(\mathrm{T})=$ «обличение привилегированного класса России XIX века», $\mathrm{p}(\mathrm{T})=$ «психологические коллизии между апатичным Обломовым, его возлюбленной и его другом» и $\mathrm{m}(\mathrm{T})$ = «реализация в современных условиях сакрального принципа “недеяния" (занимающего важное место не только в даосской практике, но и в русской культуре - можно вспомнить сказочного Емелю или былинного Илью Муромца)».

Можно заметить, что в определении трёх базовых семантических операторов нет никаких ограничений, накладываемых характером самого текста, ничто не мешает применить их вообще к любому художественному тексту. Возьмём для примера модернистский текст и не роман, а, скажем, миниатюру Ф. Кафки «Отъезд» (перевод С.К. Апта):

«Я велел вывести свою лошадь из конюшни. Слуга не понял меня. Я сам пошёл в конюшню, оседлал свою лошадь и сел на неё. Вдали я услыхал звуки трубы, я спросил его, что это значит. Он ничего не знал и ничего не слышал. У ворот он задержал меня и спросил:

- Куда ты поскачешь, господин?

- Не знаю, - сказал я, - только подальше отсюда, только подальше отсюда. Дальше и дальше, только так я могу достичь своей цели.

- Значит, ты знаешь свою цель? - спросил он.

- Да, - ответил я, - я же сказал: «подальше отсюда»- вот моя цель.

- У тебя нет с собой съестных припасов, - сказал он.
- Мне не нужно их, - сказал я, - путешествие мое такое долгое, что я умру с голода, если по пути ничего не достану. Никакие припасы мне не помогут. Это же, к счастью, поистине невероятное путешествие».

Здесь также чётко различимы три семантических уровня. К социальному уровню относится информация о материально-предметном мире (лошадь, конюшня, труба, ворота, припасы) и объективных социальных отношениях (отношения слуги и господина). К психологическому уровню относятся странные мотивы и чувства господина (слуховая галлюцинация, спешка, нежелание брать припасы) и необычная реакция слуги («допрос» господина без малейшего желания ему помочь). Заметим, что, несмотря на алогичность ситуации, психологически она изображена очень правдоподобно. Наконец, на метафизическом уровне можно уловить отзвук сакрального сюжета о «пророке», гонимом внутренним голосом, иррациональным императивом).

Мы видим, что эффект «реалистичности» возникает в результате применения к тексту специфических семантических операторов. В данной статье это применение носит эксплицитный характер, но на практике это происходит чаще всего имплицитно и ускользает от внимания интерпретатора.

Социальный реализм - это внутренняя установка интерпретатора на применение к художественному произведению семантического оператора $\hat{S}$. Аналогично психологический реализм - это внутренняя установка интерпретатора на применение семантического оператора $\hat{P}$ и метафизический реализм - внутренняя установка интерпретатора на применение семантического оператора $\hat{M}$. Реализм как таковой - это установка интерпретатора на применение к художественному произведению одного, двух или сразу трёх специфических семантических операторов из описанного нами множества $\{\hat{S}, \hat{P}, \hat{M}\}$.

Альтернативные литературные направления (романтизм, модернизм и т. д.) связаны с другими установками интерпретатора и определяются иными семантическими операторами. Мы видим, например, что миниатюру Ф. Кафки «Отъезд» принято считать модернистским, а не реалистическим текстом, хотя в ней легко выделяются все три реалистических пласта смыслов. Это связано с традицией интерпретации данного текста, поскольку сформировалась и устоялась традиция применения к этой миниатюре (как и к другим модернистским текстам и «нереалистическим» текстам вообще) иных семантических операторов, не входящих в рассмотренное нами множество $\{\hat{S}, \hat{P}, \hat{M}\}$. 


\section{4. Заключение}

За рамками нашего исследования осталась связь трёхоператорного метода с александрийским учением о троякости смысла Священного писания, которое восходит к Филону Александрийскому и Оригену и гласит, что каждое место и слово Писания имеет, по крайней мере, три смысла: телесный (буквальный, чувственный, исторический, грамматический), душевный (моральный, нравоучительный) и духовный (мистический, анагогический).

Очевидно также, что предложенный подход к проблеме реализма требует существенного пересмотра научного использования термина «реализм» и его производных (образованных по схеме «реализм + уточняющий эпитет»). Но на данном этапе нашей целью было доказать возможность кардинально иного подхода к проблеме реализма по сравнению с доминирующим сегодня классическим подходом.

Мы полагаем установленным, что классический подход к проблеме реализма основан на ошибочном допущении. Релевантная и логически непротиворечивая совокупность критериев реа- листичности $\left\{\mathrm{k}_{1}, \mathrm{k}_{2} \ldots \mathrm{k}_{\mathrm{n}}\right\}$ невозможна, поскольку текст в семантическом отношении представляет собой сосуществование трёх различных уровней, а каждый уровень определяется логически взаимоисключающими принципами (гомофония, полифония и гетерофония). Важность каждого уровня и уделяемое ему внимание зависит от интерпретатора - его навыков, знаний, принадлежности к некоторой традиции интерпретации и прагматических целей. Вообще говоря, любой текст может быть интерпретирован как повествование о некой социальной, психологической и метафизической реальности, но за некоторыми текстами закрепляется определённая традиция интерпретации, которую мы формализовали с помощью трёхоператорного метода, и именно эти тексты принято считать peaлистическими.

Смена реалистических направлений - это в действительности смена доминирующих способов интерпретации художественных текстов, а сам реализм представляет собой такой способ интерпретации, при котором художественный текст подвергается воздействию одного, двух или сразу трёх семантических операторов интерпретации из описанного нами множества $\{\hat{S}, \hat{P}, \hat{M}\}$.

\section{Список литературы:}

1. Захаров 3.Н. Реализм // Достоевский: Эстетика и поэтика. Словарь-справочник / Науч. ред. Г.К. Щенников. Челябинск: Металл, 1997.

2. Маркс К., Энгельс Ф. Об искусстве. М.: Искусство, 1957. Т. 1.

3. Степанян К.А. Явление и диалог в романах Ф.М. Достоевского. СПб.: Крига, 2010.

4. Руднев В.П. Прочь от реальности: Исследования по философии текста. М.: Аграф, 2000.

5. Достоевский Ф.М. Полное собрание сочинений: в 30 т. Л.: Наука, 1972-1990. Т. 27.

6. Бахтин М.М. Собрание сочинений: в 7 т. М.: Русские словари; Языки славянской культуры, 1997-2012. Т. 6.

7. Тороп П.Х. Симультанность и диалогизм в поэтике Достоевского // Труды по знаковым системам. Тарту, 1984. Вып. 17. С. 138-158.

8. Тороп П.Х. Перевоплощения персонажей в романе Ф. Достоевского «Преступление и наказание» // Труды по знаковым системам. Тарту, 1988. Вып. 22. С. 85-96.

9. Мамлеев Ю.В. Судьба бытия. За пределами индуизма и буддизма. М.: Эннеагон, 2006.

10. Греймас А.-Ж. Структурная семантика: Поиск метода. М.: Академический Проект, 2004.

\section{References (transliteration):}

1. Zakharov Z.N. Realizm // Dostoevskii: Estetika i poetika. Slovar'-spravochnik / Nauch. red. G.K. Shchennikov. Chelyabinsk: Metall, 1997.

2. Marks K., Engel's F. Ob iskusstve. M.: Iskusstvo, 1957. T. 1.

3. Stepanyan K.A. Yavlenie i dialog v romanakh F.M. Dostoevskogo. SPb.: Kriga, 2010.

4. Rudnev V.P. Proch' ot real'nosti: Issledovaniya po filosofii teksta. M.: Agraf, 2000.

5. $\quad$ Dostoevskii F.M. Polnoe sobranie sochinenii: v 30 t. L.: Nauka, 1972-1990. T. 27.

6. Bakhtin M.M. Sobranie sochinenii: v 7 t. M.: Russkie slovari; Yazyki slavyanskoi kul'tury, 1997-2012. T. 6.

7. Torop P.Kh. Simul'tannost' i dialogizm v poetike Dostoevskogo // Trudy po znakovym sistemam. Tartu, 1984. Vyp. 17. S. 138-158.

8. Torop P.Kh. Perevoploshcheniya personazhei v romane F. Dostoevskogo «Prestuplenie i nakazanie» // Trudy po znakovym sistemam. Tartu, 1988. Vyp. 22. S. 85-96.

9. Mamleev Yu.V. Sud'ba bytiya. Za predelami induizma i buddizma. M.: Enneagon, 2006.

10. Greimas A.-Zh. Strukturnaya semantika: Poisk metoda. M.: Akademicheskii Proekt, 2004. 